\title{
Fatigue in the acute phase after first stroke predicts poorer physical health 18 months later
}

Anners Lerdal, RN, PhD Caryl L. Gay, PhD

Correspondence to Dr. Lerdal: anners.lerdal@medisin.uio.no

\section{ABSTRACT}

Objective: To determine whether fatigue in the acute phase following stroke predicts long-term patient-reported physical and mental health outcomes 18 months later.

Methods: Patients ( $n=96$, mean age 67.8 years, SD 12.9) were assessed within 2 weeks of hospital admission for first-ever stroke (acute phase) and 18 months later. Measures included the Fatigue Severity Scale and the Beck Depression Inventory II. The Short Form-36 was used to assess selfreported physical and mental health. Multivariate regression analysis was used to evaluate the relationship between acute phase fatigue and later health outcomes, controlling for relevant covariates.

Results: Acute phase fatigue was associated with physical health at 18-month follow-up, but not with mental health. After adjusting for other potential predictors of health outcomes, including age, sex, cohabitation status, acute phase physical or mental health, and depressive symptoms, acute phase fatigue remained a significant predictor of later physical health but not of later mental health. The reverse relationships were also examined, but neither physical nor mental health in the acute phase predicted fatigue at 18 months; the best predictor of fatigue at 18-month followup was acute phase fatigue.

Conclusions: These findings suggest that acute phase fatigue is an independent risk factor for poor physical health 18 months after stroke. Diagnosis and treatment of acute phase fatigue may improve physical health-related quality of life among stroke survivors. Effective treatments for poststroke fatigue, both in the acute phase and later in the recovery period, are needed. Neurology ${ }^{\circledast}$ 2013;81:1581-1587

\section{GLOSSARY}

BDI-II = Beck Depression Inventory version II; FSS = Fatigue Severity Scale; HRQoL = health-related quality of life; ICD-10 = International Classification of Diseases, 10th revision; MCS = Mental Component Summary; MMSE = MiniMental State Examination; PCS $=$ Physical Component Summary; SF-36 = 36-item Short Form acute version; SSS = Scandinavian Stroke Scale.

Physical and mental health are key components of health-related quality of life (HRQoL) and thus important patient-reported outcomes for stroke survivors. Several cross-sectional studies have reported that poststroke fatigue, which occurs in $36 \%$ to $77 \%$ of cases, ${ }^{1-4}$ is strongly correlated with poorer HRQoL..$^{5-7}$ In addition, a longitudinal study in the Netherlands reported that higher fatigue levels 6 to 36 months following stroke were related to lower HRQoL during the same period, even when controlling for relevant covariates. ${ }^{8}$ However, to our knowledge, no studies have examined whether fatigue in the acute phase following stroke predicts longer-term HRQoL. Since fatigue may be detrimental to patients' physical and mental recovery after stroke, it is of clinical importance to understand to what degree fatigue predicts subsequent outcomes. Furthermore, the acute phase following stroke may represent a critical period for maximizing recovery, as evidenced by findings related to early mobilization. ${ }^{9,10}$ It is therefore important to understand whether fatigue, particularly during this period, is a risk factor for poorer health outcomes. Thus, the aim of this study was to determine whether poststroke fatigue in the acute phase predicts long-term physical and mental

From the Department of Research (A.L., C.L.G), Lovisenberg Diakonale Hospital, Oslo; the Department of Nursing Science (A.L.), Institute of Health and Society, Faculty of Medicine, University of Oslo, Norway; the Department of Family Health Care Nursing (C.L.G.), University of California, San Francisco; and Lovisenberg Diakonale University College (C.L.G.), Oslo, Norway.

Go to Neurology.org for full disclosures. Funding information and disclosures deemed relevant by the authors, if any, are provided at the end of the article. This is an open access article distributed under the terms of the Creative Commons Attribution-Noncommercial No Derivative 3.0 License, which permits downloading and sharing the work provided it is properly cited. The work cannot be changed in any way or used commercially. 
health outcomes 18 months after stroke. It was hypothesized that acute phase fatigue would predict both physical and mental health outcomes, even when controlling for confounding variables.

METHODS Sample and procedures. The Post-Stroke Fatigue Study is a longitudinal, observational study conducted at 2 hospitals in Norway between March 2007 and September 2008. ${ }^{11}$ Patients with first-ever stroke were recruited for the study upon hospital admission. Data were collected from medical records and in standardized interviews using validated questionnaires. To ease participant burden in the acute phase (i.e., first 2 weeks after admission), interviews were conducted at 2 different times within 48 hours. Data on HRQoL and fatigue were collected during the first interview. Follow-up data were collected 6, 12, and 18 months later. ${ }^{12}$ Most follow-up interviews were conducted in the patient's home, although for those working or traveling, the questionnaires were sent by mail and returned in a sealed envelope. Data collected in the acute phase and at 18-month follow-up were included in this report.

Study inclusion criteria were first-ever clinical presentation of stroke (either ischemic or hemorrhagic) according to the $I C D-10$ (I60-I64), ${ }^{13} \geq 18$ years of age, and sufficient cognitive functioning to participate. Patients who were fully conscious, or somnolent but could be awakened to full consciousness (equivalent to a score of 4 or 6 on item 1 in the Scandinavian Stroke Scale [SSS]) ${ }^{14}$ and oriented to time, place, and person (equivalent to a score of 4 on SSS item 6), were eligible. At one hospital those who did not meet the SSS criterion were further assessed with Mini-Mental State Examination (MMSE) and those with MMSE score $\leq 10$ or MMSE score 11 to 23 but found cognitively incompetent by a physician or nurse were excluded. At the second hospital, patients who did not meet the SSS criteria were clinically assessed by the stroke team, and those found to be cognitively impaired were excluded. Patients at both hospitals were excluded if they were unable to communicate (participate in a meaningful conversation or point to responses on questionnaires).

Of the 193 patients diagnosed with first-ever stroke, 14 were excluded due to poor cognitive functioning, 26 because of difficulty communicating due to stroke, and 1 due to inability to understand Norwegian language. Of the 152 eligible patients, 125 consented (82\%), 6 of whom died or were transferred before being interviewed, resulting in an initial sample of 119 patients. Data from 4 of the 119 patients were collected more than 15 days after admission and were excluded from this analysis of acute phase predictors of HRQoL. During the follow-up period, 8 patients died, 4 patients could not respond due to a deterioration in their health, 3 withdrew from the study, 3 did not respond, and 1 had missing HRQoL scores. The remaining 96 cases with valid responses both during the acute phase and at 18-month follow-up were included in this analysis.

Measurements. Health-related quality of life. HRQoL was measured using the 36-item Short Form acute version (SF-36) ${ }^{15}$ developed for the Medical Outcomes Study. ${ }^{16}$ Scale scores were computed and converted to standardized Physical Component Summary (PCS) scores (including the subdimensions physical functioning, role limitations due to physical problems, bodily pain, and general health) and standardized Mental Component Summary (MCS) scores (including vitality/social functioning, role limitations due to emotional problems, and mental health) ${ }^{17}$ Both the PCS and MCS scores range from 0 (poor health) to 100 (good health) and have a mean of 50 and an SD of 10 based on 1998 US population norms. ${ }^{17}$ The SF-36 has demonstrated satisfactory reliability and validity and has been thoroughly tested for psychometric properties in several countries, including Norway. ${ }^{18}$

Fatigue. The 9-item Fatigue Severity Scale (FSS) ${ }^{19}$ is the most commonly used instrument to measure fatigue in stroke and has good validity and reliability. ${ }^{20,21}$ The modified FSS-7 was previously shown to have stronger psychometric properties among stroke patient $s^{21}$ and was therefore used in this study. Patients rate their level of agreement with 7 statements about fatigue interference on a 7-point Likert scale ranging from strongly disagree to strongly agree. An FSS mean score ranging from 1 to 7 was computed for each patient, with higher scores indicating higher levels of fatigue.

Depressive symptoms. A measure of depression was included in this analysis so that the role of fatigue could be examined while controlling for its known association with depression. Depressive symptom severity was measured with the Beck Depression Inventory version II (BDI-II). The instrument consists of 21 groups of 4 or 7 statements ranged by severity of the symptom $(0-3)$, and the patient is required to select one in each group. The best possible score is 0 . Cronbach $\alpha$ for the BDI-II in this study was 0.85 . BDI-II has been found to be an acceptable screening instrument for depression in stroke patients. ${ }^{22}$

Sociodemographic variables. Data on age, sex, and cohabitation status (living with a spouse/partner or not) were collected from the medical record, while data on level of formal education (less than 12 years vs 12 years or more) were collected from a questionnaire. Those in paid work or self-employment were categorized as working, while all others (students, military service, full-time homemakers, and disability or old age pension) were categorized as not working.

Stroke type and location. CT scans were taken of all patients on admission to the hospital. Stroke type was categorized as one of the following: ischemic infarct, hemorrhage, or unknown based on the radiologist's description. If an additional CT scan was taken, the latest description was used for categorizing. Stroke location was grouped as left, right, bilateral, or unknown. If the CT scan showed signs of lesions from previous undiagnosed strokes, such lesions were included in the classification of stroke.

Statistical analysis. Descriptive statistics were used to summarize sociodemographic and clinical characteristics. Associations between variables were assessed using Pearson correlations. Paired $t$ tests were used to compare fatigue and health outcomes in the acute phase and at 18 months. A multivariate linear regression analysis was conducted to evaluate the relationship between acute phase fatigue and HRQoL outcomes, while controlling for relevant covariates. Separate regression models were fit predicting physical and mental health. Acute phase physical or mental health was included in the model to account for baseline differences in functioning and stroke severity. In addition, any demographic or clinical variable that was correlated $(r \geq 0.15)$ with fatigue or with mental or physical health, either in the acute phase or at 18-month followup, was also included as a covariate. The extent to which each step improved the model was evaluated by testing the significance of the associated change in $R^{2}$. Since $R^{2}$ reflects the goodness of fit of the regression model and the proportion of variance in the dependent variable that is explained by the independent variables, the change in $R^{2}$ evaluates the incremental variance explained by each step of the model. The level of significance was set at $p<0.05$, and all tests were 2 -tailed. A sample size of 100 for an effect size of 0.24 gives the power of 0.80 for general statistical analysis. The data were analyzed using SPSS for Windows version 17.0 (SPSS Inc., Chicago, IL).

Standard protocol approvals, registrations, and patient consents. The study was approved by the Regional Medical 
Table 1 Sample characteristics in the acute phase and physical and mental health scores at 18-month follow-up $(n=96)$

\begin{tabular}{|c|c|c|c|}
\hline \multirow[b]{2}{*}{$\begin{array}{l}\text { Demographic and stroke } \\
\text { characteristics }\end{array}$} & \multirow[b]{2}{*}{$\begin{array}{l}\text { Mean (SD) } \\
\text { or } n(\%)\end{array}$} & \multicolumn{2}{|c|}{ Outcomes at 18 months } \\
\hline & & $\begin{array}{l}\text { Physical health } \\
\text { (PCS score) }\end{array}$ & $\begin{array}{l}\text { Mental health } \\
\text { (MCS score) }\end{array}$ \\
\hline Age, y & 67.8 (12.9) & & \\
\hline$<65$ & 37 (39) & $47.4(10.3)^{a}$ & $51.4(9.7)$ \\
\hline$\geq 65$ & $59(61)$ & $41.8(11.0)^{a}$ & $50.6(10.1)$ \\
\hline \multicolumn{4}{|l|}{ Sex } \\
\hline Male & $57(59)$ & $45.2(11.1)$ & $50.0(9.8)$ \\
\hline Female & $39(41)$ & $42.2(10.9)$ & $52.3(10.0)$ \\
\hline \multicolumn{4}{|l|}{ Cohabitation status } \\
\hline Living with spouse/partner & $61(64)$ & $45.5(11.0)$ & $52.3(9.0)$ \\
\hline Not living with spouse/partner & $35(36)$ & $41.3(10.8)$ & $48.6(11.2)$ \\
\hline \multicolumn{4}{|l|}{ Work status at baseline } \\
\hline Working & $23(24)$ & $49.6(8.0)^{a}$ & $52.2(8.7)$ \\
\hline Not working & $73(76)$ & $42.2(11.3)^{a}$ & 50.5 (10.3) \\
\hline \multicolumn{4}{|l|}{ Work status at 18 months $(n=94)$} \\
\hline Working & $15(16)$ & $51.7(4.8)^{a}$ & $52.6(7.3)$ \\
\hline Not working & $79(84)$ & $42.5(11.3)^{a}$ & $50.7(10.4)$ \\
\hline \multicolumn{4}{|l|}{ Stroke type } \\
\hline Infarct & 75 (78) & $44.0(11.1)$ & $50.5(10.4)$ \\
\hline Hemorrhage & $7(7)$ & $42.0(11.6)$ & $50.2(7.7)$ \\
\hline Unknown & $14(15)$ & $44.8(11.1)$ & $53.4(8.0)$ \\
\hline \multicolumn{4}{|l|}{ Stroke location $(n=75)$} \\
\hline Right & 27 (36) & 42.8 (11.9) & 51.9 (10.5) \\
\hline Left & 24 (32) & $46.3(9.1)$ & 48.3 (10.3) \\
\hline Bilateral & $15(20)$ & 44.5 (13.1) & $51.3(12.1)$ \\
\hline Unknown & $9(12)$ & 40.7 (10.5) & 51.2 (7.9) \\
\hline
\end{tabular}

Abbreviations: MCS = Mental Component Summary; PCS = Physical Component Summary . Summary scores are standardized based on US population norms, which have a mean of 50 and an SD of 10.

${ }^{\mathrm{a}} \mathrm{p}<0.05$.

Research Ethics Committee of Health East of Norway (2.2007.90), the Norwegian Data Inspectorate, and the hospital approval units for security of personal data. Informed written consent was obtained from all patients.

Table 2 Measures of fatigue, depressive symptoms, and mental and physical health in the acute phase and 18 months after stroke $(n=96)$

Measure
Fatigue (FSS-7)
Depressive symptoms (BDI-II)
Mental health (MCS)
Physical health (PCS)

Acute phase, mean (SD)

$3.83(1.37)$

9.40 (7.51)

49.3 (11.1)

40.9 (10.0) 18-month follow-up mean (SD)

3.77 (1.58)

$9.50(7.21)$

50.9 (9.9)

$44.0(11.0)^{a}$
Abbreviations: BDI-II = Beck Depression Inventory version II; FSS = Fatigue Severity Scale; MCS $=$ Mental Component Summary; PCS = Physical Component Summary.

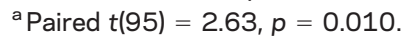

RESULTS Sociodemographic and clinical characteristics for patients are summarized in table 1, along with each variable's association with self-reported physical and mental health outcomes. Patients from the 2 hospitals did not differ demographically, clinically, or on measures of fatigue, depression, or physical or mental health. Better physical health was associated with younger age and work status, while mental health was unrelated to sociodemographic and clinical characteristics. As shown in table 2, physical health scores improved between the acute phase and 18-month follow-up, but mental health, fatigue, and depressive symptom scores did not change significantly over time.

Pearson correlations between acute phase characteristics and 18-month outcomes are summarized in table 3. Acute phase fatigue was associated with physical and mental health during the acute phase, but was only associated with physical health at the 18-month follow-up. Depressive symptoms during the acute phase were associated with physical and mental health, both during the acute phase and at 18 months. Physical and mental health were correlated with each other during the acute phase, but not at follow-up. Physical health in the acute phase was associated with physical health at 18 months; likewise, mental health in the acute phase was associated with mental health at follow-up.

Hierarchical multiple regression analyses were conducted to evaluate the extent to which acute phase fatigue predicts HRQoL at 18 months after stroke while controlling for relevant covariates. Each model included age, sex, cohabitation status, and acute phase depressive symptoms. The model predicting physical health at 18 months also included acute phase physical health to account for baseline functioning, while the model predicting mental health at 18 months included acute phase mental health. As shown in table 4 , acute phase fatigue was a significant predictor of physical health at 18 months, even when accounting for baseline physical health and other relevant variables. In contrast, acute phase fatigue was not a significant predictor of mental health at 18 months after accounting for baseline mental health (table 5). Given the conceptual overlap between mental health and depressive symptoms, the analysis in table 5 was repeated without depressive symptoms as a covariate, but the role of fatigue remained insignificant.

The temporal relationships between fatigue and physical and mental health were also examined in the reverse direction to determine whether physical or mental health in the acute phase was predictive of fatigue 18 months later. Like the models presented in tables 4 and 5, the reverse models controlled for age, sex, cohabitation status, and depressive symptoms in the acute phase. However, the dependent variable was changed to fatigue at 18 months and the remaining independent variables were changed 


\begin{tabular}{|c|c|c|c|c|c|c|c|c|c|}
\hline \multirow[t]{2}{*}{ Table 3} & \multicolumn{9}{|c|}{$\begin{array}{l}\text { Pearson correlations between preexisting patient characteristics, clinical predictors in the acute phase after stroke, and mental and } \\
\text { physical health outcomes at 18-month follow-up }(n=96)\end{array}$} \\
\hline & Age & Sex & Cohabitation & $\begin{array}{l}\text { Depressive } \\
\text { symptoms }\end{array}$ & $\begin{array}{l}\text { Fatigue, acute } \\
\text { phase }\end{array}$ & $\begin{array}{l}\text { Physical health, } \\
\text { acute phase }\end{array}$ & $\begin{array}{l}\text {, Mental health, } \\
\text { acute phase }\end{array}$ & $\begin{array}{l}\text { Fatigue, } \\
18 \text { months }\end{array}$ & $\begin{array}{l}\text { Physical health, } \\
18 \text { months }\end{array}$ \\
\hline \multicolumn{10}{|c|}{ Demographic characteristics } \\
\hline \multicolumn{10}{|l|}{ Age } \\
\hline Sex $^{a}$ & 0.171 & & & & & & & & \\
\hline Cohabitation $^{\mathrm{b}}$ & $-0.324^{c}$ & -0.123 & & & & & & & \\
\hline \multicolumn{10}{|l|}{ Acute phase predictors } \\
\hline Depressive symptoms & s 0.028 & 0.152 & $-0.306^{c}$ & & & & & & \\
\hline Fatigue & -0.017 & 0.157 & -0.078 & $0.465^{c}$ & & & & & \\
\hline Physical health & -0.041 & -0.065 & 0.106 & $-0.266^{c}$ & $-0.402^{c}$ & & & & \\
\hline Mental health & 0.091 & -0.097 & 0.174 & $-0.362^{c}$ & $-0.399^{c}$ & $-0.224^{c}$ & & & \\
\hline \multicolumn{10}{|l|}{ Outcomes at 18 months } \\
\hline Fatigue & 0.114 & 0.100 & -0.126 & $0.211^{c}$ & $0.409^{c}$ & $-0.227^{c}$ & $-0.207^{c}$ & & \\
\hline Physical health & $-0.292^{c}$ & -0.134 & 0.187 & $-0.202^{c}$ & $-0.346^{c}$ & $0.413^{c}$ & 0.005 & $-0.612^{c}$ & \\
\hline Mental health & -0.053 & 0.113 & 0.178 & $-0.257^{c}$ & -0.186 & -0.104 & $0.287^{c}$ & $-0.352^{c}$ & -0.144 \\
\hline
\end{tabular}

to acute phase fatigue and either physical or mental health. Neither physical nor mental health during the acute phase was predictive of later fatigue (data not shown); the only predictor of fatigue at 18 months was fatigue in the acute phase $(p=0.001)$.

DISCUSSION This study describes the longitudinal relationship between fatigue in the acute phase after stroke and patients' perceived health 18 months later. In this study, acute phase fatigue did not predict mental health, but was directly related to and predicted lower physical health at 18-month follow-up, even after controlling for sociodemographic variables and the patients' physical health and depressive symptoms in the acute phase. By controlling for acute phase physical health, the role of acute phase fatigue is distinguished from other characteristics known to predict later physical health, such as prestroke health, comorbidity, stroke severity, and degree of functional impairment. By also controlling for depressive

\begin{tabular}{|c|c|c|c|c|c|c|c|}
\hline Table & $\begin{array}{l}\text { Hierarchical regressic } \\
\text { up }(n=96)\end{array}$ & analysis predi & physical h & ealth in the a & acute phase a & nd at $18-\mathrm{mc}$ & onth follow- \\
\hline \multirow[b]{2}{*}{ Step } & \multirow[b]{2}{*}{ Predictors } & \multicolumn{3}{|c|}{$\begin{array}{l}\text { Predicting physical health in the } \\
\text { acute phase }\end{array}$} & \multicolumn{3}{|c|}{$\begin{array}{l}\text { Predicting physical health at } 18 \\
\text { months }\end{array}$} \\
\hline & & Final $\beta$ & $p$ & $\Delta R^{2}$ & Final $\beta$ & $p$ & $\Delta R^{2}$ \\
\hline \multirow[t]{5}{*}{1} & Demographic characteristics & & & 0.014 & & & $0.101^{a}$ \\
\hline & Age in years & -0.034 & 0.743 & & -0.261 & 0.008 & \\
\hline & Sex $($ male $=0$, female $=1)$ & 0.016 & 0.870 & & -0.030 & 0.747 & \\
\hline & Cohabitation $($ no $=0$, yes $=1)$ & 0.043 & 0.692 & & 0.052 & 0.600 & \\
\hline & Acute phase predictors & & & & & & \\
\hline 2 & Physical health (PCS) & - & - & - & 0.308 & 0.002 & $0.152^{\mathrm{a}}$ \\
\hline 3 & Depressive symptoms (BDI-II) & -0.086 & 0.452 & $0.058^{a}$ & 0.012 & 0.912 & 0.005 \\
\hline 4 & Fatigue (FSS-7) & -0.362 & 0.001 & $0.101^{\mathrm{a}}$ & -0.223 & 0.041 & $0.034^{a}$ \\
\hline Full $n$ & odel statistics & $F_{5,90}=3.78$ & $p=0.004$ & $R^{2}=0.128$ & $F_{6,89}=6.11$ & $p<0.001$ & $\begin{array}{l}\text { Adjusted } \\
R^{2}=0.244\end{array}$ \\
\hline
\end{tabular}

Abbreviations: BDI-II = Beck Depression Inventory version II; FSS = Fatigue Severity Scale; PCS = Physical Component Summary.

Dependent variable $=$ Short Form-36 PCS score.

${ }^{a} p<0.05$. 
Table 5 Hierarchical regression analysis predicting mental health in the acute phase and at 18-month follow-up ( $n=96)$

\begin{tabular}{|c|c|c|c|c|c|c|c|}
\hline \multirow[b]{2}{*}{ Step } & \multirow[b]{2}{*}{ Predictors } & \multicolumn{3}{|c|}{ Predicting mental health in the acute phase } & \multicolumn{3}{|c|}{ Predicting mental health at 18 months } \\
\hline & & Final $\beta$ & $p$ & $\Delta \mathbf{R}^{2}$ & Final $\beta$ & $\mathbf{p}$ & $\Delta \mathbf{R}^{2}$ \\
\hline \multirow[t]{5}{*}{1} & Demographic characteristics & & & 0.064 & & & 0.051 \\
\hline & Age & 0.141 & 0.162 & & -0.073 & 0.494 & \\
\hline & Sex $($ male $=0$, female $=1)$ & -0.030 & 0.753 & & 0.189 & 0.063 & \\
\hline & Cohabitation (no $=0$, yes $=1$ ) & 0.137 & 0.190 & & 0.089 & 0.422 & \\
\hline & Acute phase predictors & & & & & & \\
\hline 2 & Mental health (MCS) & - & - & - & 0.221 & 0.049 & $0.077^{a}$ \\
\hline 3 & Depressive symptoms (BDI-II) & -0.182 & 0.103 & $0.092^{a}$ & 0.153 & 0.198 & 0.024 \\
\hline 4 & Fatigue (FSS-7) & -0.296 & 0.006 & $0.068^{a}$ & -0.050 & 0.665 & 0.002 \\
\hline \multicolumn{2}{|c|}{ Full model statistics } & $F_{5,90}=5.19$ & $p<0.001$ & $\begin{array}{l}\text { Adjusted } \\
R^{2}=0.181\end{array}$ & $F_{6,89}=2.69$ & $p=0.019$ & $\begin{array}{l}\text { Adjusted } \\
R^{2}=0.096\end{array}$ \\
\hline
\end{tabular}

Abbreviations: BDI-II = Beck Depression Inventory version II; FSS = Fatigue Severity Scale; MCS = Mental Component Summary.

Dependent variable $=$ Short Form-36 MCS score. Given the conceptual overlap between mental health and depressive symptoms, the analyses were repeated without including BDI-II scores; the role of fatigue was unchanged. ${ }^{a} p<0.05$.

symptoms, which often co-occur with fatigue, these findings indicate that acute phase fatigue is an independent risk factor for poor long-term physical health following stroke and is not only a manifestation of depression. Moreover, it does not seem that fatigue and physical health are merely changing together over time, since physical health during the acute phase did not predict later fatigue.

These findings of acute phase fatigue are generally consistent with those of correlational studies of fatigue later in the recovery period (ranging from 3 months to 2 years after stroke). ${ }^{7,23}$ Associations between poststroke fatigue and concurrent physical functioning have also been reported in cross-sectional studies. ${ }^{24-26}$ Furthermore, our study showed that acute phase fatigue was correlated with concurrent mental health and depressive symptoms, similar to other studies reporting associations between poststroke fatigue and mental health indicators. ${ }^{26-28}$ However, while our findings indicated concurrent associations, we did not find longitudinal relationships between fatigue and mental health. Thus, our results suggest a stronger connection between fatigue and physical health, in contrast with other findings, ${ }^{7}$ which indicate a stronger relationship with mental health.

The findings of this study are also consistent with other longitudinal studies that have found fatigue to be associated with subsequent health outcomes. Two studies have shown that fatigue after stroke (either within 6 months or 2 years after stroke) predicts death in the following year, even when accounting for other background variables. ${ }^{23,29}$ Fatigue was also identified as an independent risk factor for poor
HRQoL at 6, 12, and 36 months following stroke. ${ }^{8}$ In contrast to our findings emphasizing the relationship between acute phase fatigue and subsequent physical health, a recent study of fatigue 6 and 12 months following stroke reported that cognitive impairment and affective symptoms were strongly associated with poststroke fatigue and likely play an important role in its development. ${ }^{30}$

Although it is often assumed that factors correlated with fatigue are involved in its development, the results of this study suggest that acute phase fatigue is involved in the development of physical health over time. It may be that fatigue in the acute phase limits patients' participation during a critical, early phase of rehabilitation and thus interferes with long-term recovery. Our finding indicates that fatigue management ought to be included in clinical guidelines for stroke treatment and rehabilitation. From a clinical perspective, it would be desirable to know whether treatment of acute phase fatigue contributes to better rehabilitation outcomes.

It should be noted that the physical health ratings during the acute phase were approximately 1 SD below the norm for the general population. While scores improved significantly over the course of the study, at 18 months there was still a clinically significant difference between the physical health ratings of this sample and general population norms (Cohen $d=0.57) .{ }^{31}$ In contrast, the mental health ratings were similar to the general population mean both in the acute phase and 18 months later, and did not significantly change over the course of the study. Lower scores on measures of physical health relative 
to measures of mental health is consistent with previous findings ${ }^{32}$ among individuals following stroke.

The results of this study should be considered in light of its strengths and limitations. Use of a validated and established HRQoL measure in both the acute phase and at 18-month follow-up made it possible to control for the patients' physical and mental health in the acute phase when examining acute phase fatigue as a predictor of subsequent outcome. Furthermore, this longitudinal study evaluated the temporal relationships between acute phase fatigue and HRQoL 18 months later, which cannot be examined in cross-sectional studies. The measure of fatigue (FSS-7) used in this study emphasized how a person's level of fatigue interferes with daily life. Other aspects, such as perceptions of fatigue and performance fatigability, ${ }^{33}$ also need to be explored in future studies. This study utilized a systematic sampling approach, and had high participation and retention rates over the course of the study, thereby reducing the risk of sampling or retention bias and increasing generalizability of the findings. Nonetheless, severely depressed patients may have been less likely to participate and thus may be underrepresented in the study sample. Furthermore, patients with recurrent stroke and patients with insufficient cognitive or communication skills were excluded from the study, and thus, the findings cannot be generalized to these patient groups. Norway also offers comprehensive rehabilitation services as part of the national health care system, and thus findings on health outcomes might not generalize to patients with more limited health care services. A small number of participants did not meet the objective criteria for cognitive status (i.e., SSS or MMSE) but were included based on clinical judgment of cognitive competence to participate. However, given the small number and their ability to complete the consent process and questionnaires, it is not expected that their inclusion had an undue influence on the study, and in fact, may have somewhat increased its generalizability. This study did not include a cognitive assessment at the 18-month follow-up, and thus, the role of this potentially confounding variable could not be evaluated. Finally, data on stroke characteristics were limited to type and general location and the small number of hemorrhagic strokes limited our ability to effectively evaluate the role of stroke type. However, most studies that have included more detailed information on stroke characteristics have not found them to be significant predictors of poststroke fatigue. $2,23,27,30,34,35$

This study extends the findings of prior studies showing that poststroke fatigue is likely to persist over time ${ }^{12,30}$ and to affect later physical HRQoL. This is true not only for patients who experience fatigue later in the recovery period, but also for patients who experience fatigue in the first few weeks following stroke. Thus, future research might focus on developing interventions that target fatigue early in the recovery period, rather than waiting until fatigue has noticeable, and possibly irreversible, effects on physical health.

\section{AUTHOR CONTRIBUTIONS}

Dr. Lerdal: study concept and design, data collection, statistical analysis and interpretation, and drafting/revising the manuscript. Dr. Gay: statistical analysis and interpretation and drafting/revising the manuscript.

\section{ACKNOWLEDGMENT}

The authors thank research fellow Linda N. Bakken, research assistant Gunn Pedersen, and various staff members of Buskerud Hospital Trust in Drammen and Oslo University Hospital-Aker in Oslo, Norway.

\section{STUDY FUNDING}

Supported by the Research Council of Norway (grant 176503) and Buskerud University College, Drammen, Norway, from 2006 to 2010. This article stems from the research project "Post-stroke Fatigue" for which Dr. Suzie Kim Hesook is the project director and Drs. Grethe Eilertsen, Anners Lerdal, and Heidi Ormstad are the principal researchers.

\section{DISCLOSURE}

A. Lerdal received funding from the Research Council of Norway (Leif Eriksson Scholarship grant 19256), the Norwegian Nurses Organization, and the US-Norway Fulbright Foundation. C. Gay reports no disclosures. Go to Neurology.org for full disclosures.

Received April 16, 2013. Accepted in final form June 24, 2013.

\section{REFERENCES}

1. van Eijsden HM, van de Port IG, Visser-Meily JM, Kwakkel G. Poststroke fatigue: who is at risk for an increase in fatigue? Stroke Res Treat 2012;2012:863978.

2. Lynch J, Mead G, Greig C, Young A, Lewis S, Sharpe M. Fatigue after stroke: the development and evaluation of a case definition. J Psychosom Res 2007;63:539-544.

3. Carlsson GE, Forsberg-Warleby G, Moller A, Blomstrand C. Comparison of life satisfaction within couples one year after a partner's stroke. J Rehabil Med 2007;39:219224.

4. Naess H, Lunde L, Brogger J. The triad of pain, fatigue and depression in ischemic stroke patients: the Bergen Stroke Study. Cerebrovasc Dis 2012;33:461-465.

5. Naess H, Waje-Andreassen U, Thomassen L, Nyland H, Myhr KM. Health-related quality of life among young adults with ischemic stroke on long-term follow-up. Stroke 2006;37:1232-1236.

6. Naess H, Lunde L, Brogger J. The effects of fatigue, pain, and depression on quality of life in ischemic stroke patients: the Bergen Stroke Study. Vasc Health Risk Manag 2012;8:407-413.

7. Tang WK, Lu JY, Chen YK, Mok VC, Ungvari GS, Wong KS. Is fatigue associated with short-term healthrelated quality of life in stroke? Arch Phys Med Rehabil 2010;91:1511-1515.

8. van de Port I, Kwakkel G, Schepers VP, Heinemans CT, Lindeman E. Is fatigue an independent factor associated with activities of daily living, instrumental activities of daily living and health-related quality of life in chronic stroke? Cerebrovasc Dis 2007;23:40-45.

9. Craig LE, Bernhardt J, Langhorne P, Wu O. Early mobilization after stroke: an example of an individual patient data meta-analysis of a complex intervention. Stroke 2010; 41:2632-2636 
10. Cumming TB, Thrift AG, Collier JM, et al. Very early mobilization after stroke fast-tracks return to walking: further results from the phase II AVERT randomized controlled trial. Stroke 2011;42:153-158.

11. Lerdal A, Bakken LN, Rasmussen EF, et al. Physical impairment, depressive symptoms and pre-stroke fatigue are related to fatigue in the acute phase after stroke. Disabil Rehabil 2011;33:334-342.

12. Lerdal A, Lee KA, Bakken LN, Finset A, Kim HS. The course of fatigue during the first 18 months after first-ever stroke: a longitudinal study. Stroke Res Treat 2012;2012:126275.

13. World Health Organization. International Classification of Diseases (ICD). Available at: apps.who.int/classifications/ apps/icd/icd10online. Accessed April 13, 2011.

14. Scandinavian Stroke Study Group. Multicenter trial of hemodilution in ischemic stroke: background and study protocol. Stroke 1985;16:885-890.

15. Ware J, Snow KK, Kosinski M. SF-36 Health Survey: Manual and Interpretation Guide. Lincon, RI: Quality Metric Incorporated; 2002.

16. McHorney CA, Ware JE Jr, Rogers W, Raczek AE, Lu JF. The validity and relative precision of MOS short- and long-form health status scales and Dartmouth COOP charts: results from the Medical Outcomes Study. Med Care 1992;30(suppl 5):MS253-MS265.

17. Ware JE, Kosinski MA, Turner-Bowker DM, Gandek B. How to Score: Version 2 of the SF-12v2 Health Survey. Lincoln, RI: Quality Metric Incorporated; 2005.

18. Loge JH, Kaasa S. Short Form 36 (SF-36) health survey: normative data from the general Norwegian population. Scand J Soc Med 1998;26:250-258.

19. Krupp LB, LaRocca NG, Muir-Nash J, Steinberg AD. The Fatigue Severity Scale: application to patients with multiple sclerosis and systemic lupus erythematosus. Arch Neurol 1989;46:1121-1123.

20. Lerdal A, Bakken LN, Kouwenhoven SE, et al. Poststroke fatigue: a review. J Pain Symptom Manage 2009;38:928-949.

21. Lerdal A, Kottorp A. Psychometric properties of the Fatigue Severity Scale: Rasch analyses of individual responses in a Norwegian stroke cohort. Int J Nurs Stud 2011;48:1258-1265.

22. Aben I, Verhey F, Lousberg R, Lodder J, Honig A. Validity of the Beck Depression Inventory, Hospital Anxiety and Depression Scale, SCL-90, and Hamilton Depression Rating Scale as screening instruments for depression in stroke patients. Psychosomatics 2002;43:386-393.

23. Glader EL, Stegmayr B, Asplund K. Poststroke fatigue: a 2-year follow-up study of stroke patients in Sweden. Stroke 2002;33:1327-1333.

24. Choi-Kwon S, Han SW, Kwon SU, Kim JS. Poststroke fatigue: characteristics and related factors. Cerebrovasc Dis 2005;19:84-90.

25. Ingles JL, Eskes GA, Phillips SJ. Fatigue after stroke. Arch Phys Med Rehabil 1999;80:173-178.

26. Naess H, Nyland HI, Thomassen L, Aarseth J, Myhr KM. Fatigue at long-term follow-up in young adults with cerebral infarction. Cerebrovasc Dis 2005;20:245-250.

27. Schepers VP, Visser-Meily AM, Ketelaar M, Lindeman E. Poststroke fatigue: course and its relation to personal and stroke-related factors. Arch Phys Med Rehabil 2006;87: 184-188.

28. Choi-Kwon S, Choi J, Kwon SU, Kang DW, Kim JS. Fluoxetine is not effective in the treatment of post-stroke fatigue: a double-blind, placebo-controlled study. Cerebrovasc Dis 2007;23:103-108.

29. Naess H, Lunde L, Brogger J, Waje-Andreassen U. Fatigue among stroke patients on long-term follow-up: The Bergen Stroke Study. J Neurol Sci 2012;312:138-141.

30. Radman N, Staub F, Aboulafia-Brakha T, Berney A, Bogousslavsky J, Annoni JM. Poststroke fatigue following minor infarcts: a prospective study. Neurology 2012;79:1422-1427.

31. Cohen J. A power primer. Psychol Bull 1992;112:155-159.

32. Suenkeler IH, Nowak M, Misselwitz B, et al. Timecourse of health-related quality of life as determined 3, 6 and 12 months after stroke. Relationship to neurological deficit, disability and depression. J Neurol 2002;249:1160-1167.

33. Kluger BM, Krupp LB, Enoka RM. Fatigue and fatigability in neurologic illnesses: proposal for a unified taxonomy. Neurology 2013;80:409-416.

34. Appelros P. Prevalence and predictors of pain and fatigue after stroke: a population-based study. Int J Rehabil Res 2006;29:329-333.

35. Carlsson GE, Moller A, Blomstrand C. Consequences of mild stroke in persons $<75$ years: a 1 -year follow-up. Cerebrovasc Dis 2003;16:383-388.

\section{Save These Dates for AAN CME Opportunities!}

Mark these dates on your calendar for exciting continuing education opportunities, where you can catch up on the latest neurology information.

\section{AAN Annual Meeting}

- April 26-May 3, 2014, Philadelphia, Pennsylvania, Pennsylvania Convention Center 


\section{Neurology}

Fatigue in the acute phase after first stroke predicts poorer physical health 18 months later

Anners Lerdal and Caryl L. Gay

Neurology 2013;81;1581-1587 Published Online before print September 27, 2013

DOI 10.1212/WNL.0b013e3182a9f471

This information is current as of September 27, 2013

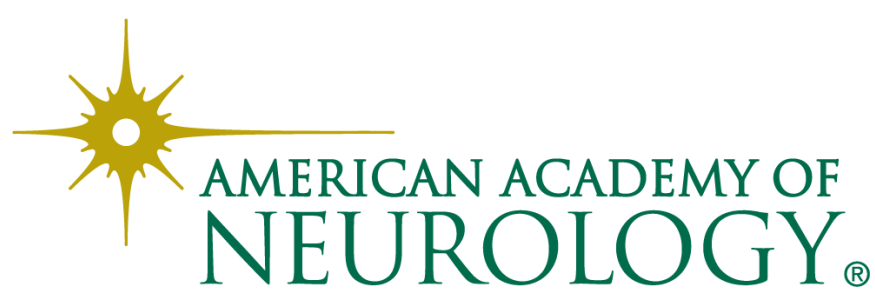




\section{Updated Information \& Services}

\section{Supplementary Material}

\section{References}

Citations

Subspecialty Collections

Permissions \& Licensing

\section{Reprints}

including high resolution figures, can be found at: http://n.neurology.org/content/81/18/1581.full

Supplementary material can be found at: http://n.neurology.org/content/suppl/2013/09/27/WNL.0b013e3182a9f 471.DC1 http://n.neurology.org/content/suppl/2014/08/06/WNL.0b013e3182a9f 471.DC2

This article cites 32 articles, 7 of which you can access for free at: http://n.neurology.org/content/81/18/1581.full\#ref-list-1

This article has been cited by 2 HighWire-hosted articles: http://n.neurology.org/content/81/18/1581.full\#\#otherarticles

This article, along with others on similar topics, appears in the following collection(s):

\section{All Rehabilitation}

http://n.neurology.org/cgi/collection/all_rehabilitation

\section{Infarction}

http://n.neurology.org/cgi/collection/infarction

Outcome research

http://n.neurology.org/cgi/collection/outcome_research

Quality of life

http://n.neurology.org/cgi/collection/quality_of_life

Information about reproducing this article in parts (figures,tables) or in its entirety can be found online at:

http://www.neurology.org/about/about_the_journal\#permissions

Information about ordering reprints can be found online:

http://n.neurology.org/subscribers/advertise

Neurology ${ }^{\circledR}$ is the official journal of the American Academy of Neurology. Published continuously since 1951, it is now a weekly with 48 issues per year. Copyright @ 2013 American Academy of Neurology. All rights reserved. Print ISSN: 0028-3878. Online ISSN: 1526-632X.

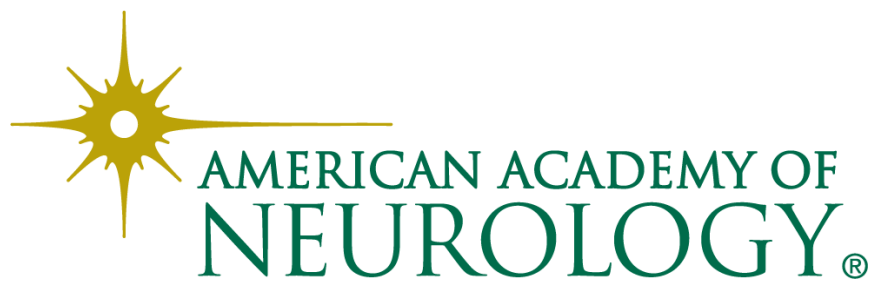

